\title{
MEASUREMENT OF HYDROGEN EMBRITTLEMENT RESISTANCE OF ALLOYS 718 AND CUSTOM AGE 625 PLUS® USING THE RISING STEP LOAD TECHNIQUE
}

\author{
Samuel J. Kernion ${ }^{1}$, John H. Magee ${ }^{1}$, Thomas N. Werley ${ }^{1}$, Paul B. Maxwell ${ }^{1}$, Brian P. \\ Somerday $^{2}$ \\ ${ }^{1}$ Carpenter Technology Corporation; \\ 101 W. Bern St.; Reading, PA 19601, USA \\ ${ }^{2}$ Sandia National Laboratories; \\ Livermore, CA 94551, USA
}

Keywords: Hydrogen environment assisted cracking, fracture mechanics, Ni-base superalloys

\begin{abstract}
Hydrogen embrittlement continues to pose a serious threat to Ni-base superalloys in oil and gas well applications. A study on the hydrogen embrittlement resistance of alloys 718 and Custom Age 625 PLUS $^{(\mathbb{R}}$ was conducted using a rising step load (RSL) technique in four point bending with sample exposure to hydrogen occurring prior to testing (internal hydrogen) or in-situ (external hydrogen). The RSL method measures the stress intensity factor required to cause propagation of a pre-existing flaw. This test is accelerated compared to other fracture mechanics based methods and provides an absolute rather than relative measure of embrittlement resistance. Results indicate hydrogen embrittlement susceptibility is dependent on composition, microstructure, and strength of the alloy. The advantages and challenges associated with this testing will be discussed, with the goal of establishing a method that can rank alloys and provide quantitative measures usable in fracture mechanics life cycle prediction and alloy design modeling.
\end{abstract}

\section{Introduction}

Oil and gas wells rely on alloys that possess excellent mechanical properties and corrosion resistance to meet ever increasing and demanding design goals. Components in deep sea wells, such as bolts and fasteners, are expected to perform for decades and replacement can be prohibitively expensive[1]. Other environments, such as high pressure, high temperature (HPHT) oil and gas wells, defined as wells operating above $150^{\circ} \mathrm{C}$ and $70 \mathrm{MPa}$, also provide a challenging operating environment for many alloy systems[2]. Failure of a component in any well is a safety hazard and can cause harm to the environment. Ni-base precipitation hardened (PH) superalloys provide a unique combination of high strength, toughness, and resistance to environmental attack that make them attractive alloys for these applications. However, unexpected field failures of these alloys attributed to hydrogen environment assisted cracking (HEAC) has underscored the importance of characterizing the response of these alloys to environments containing hydrogen[3].

Alloy 718 (UNS N07718) is the primary Ni-base superalloy deployed in oil and gas applications due to its excellent mechanical properties and good corrosion resistance. For oil and gas applications, the chemistry and heat treatment differs from the aerospace AMS 5662 specification in order to reduce the potential for HEAC, resulting in a modified microstructure and lower strength level specified in API 6A718[4]. Specifically, Nb content is lowered and a 
higher annealing temperature is employed in order to reduce or eliminate $\delta$ phase. The $\delta$ phase is considered deleterious to HEAC resistance, at least partially due to the acicular shape of the precipitate and location at grain boundaries. The concentration of $\mathrm{C}$ is also limited to 0.045 weight $\%$ to inhibit continuous grain boundary precipitation and a higher ageing temperature is used to keep hardness $<40$ HRC. This condition was developed due to extensive study of the alloy, with characterization still on-going[5]-[10]. HEAC resistance has been widely studied in other alloy systems[11], but only a few Ni-base PH superalloys have been characterized [12][14] and a broad study has not taken place on alloys with the potential to replace alloy 718 . One such Ni-base PH superalloy, Custom Age 625 PLUS $^{\circledR}$ (UNS N07716), is of interest because it can possess a yield strength of $965 \mathrm{MPa}$ or greater combined with a pitting resistance equivalent number $>40$.

Testing of an alloy's HEAC resistance involves application of a load either after exposing a specimen to hydrogen (internal hydrogen) or in-situ while the hydrogen charging is taking place (external hydrogen). Internal hydrogen testing is advantageous when hydrogen diffusion rates are limited, as is the case for face-centered cubic (fcc) Ni-base superalloys; however, testing HEAC resistance with external hydrogen may be more related to the hydrogen exposure likely seen in service. The effects of low hydrogen diffusivity can also be accommodated by measuring the relative loss in ductility or time to fracture of a smooth bar tension specimen strained at a low, constant rate while exposed to hydrogen[6], [8]. In this case, hydrogen only needs to diffuse into the near surface region for ductility and time to fracture to be affected. This slow strain rate method does not provide absolute values useful in component design.

Fracture mechanics based tests can provide the threshold stress intensity factor for subcritical crack growth $\left(\mathrm{K}_{\mathrm{Th}}\right)$, which can be utilized to predict performance. Standardized methods include constant displacement tests on bolt loaded or double cantilever beam specimens outlined in ASTM E1681[15] and NACE TM0177 Method D[16]. In both cases, a load is applied on the pre-cracked specimen, which is held in displacement control during exposure to hydrogen. ASTM E 1681 suggests 5,000-10,000 hour test duration in order to assure a valid $\mathrm{K}_{\mathrm{Th}}$ in steels. In addition to the long test times, specimens are difficult to machine and non-planar crack growth can result in invalid tests. The rising step load (RSL) technique operates under the same fracture mechanics based principles, but instead of a single initial load the load is applied in discrete steps on an single edge notch bend (SENB) pre-cracked specimen held in four point bending[17]. Each step is held for a specified length of time under displacement control before more load is applied. The load drop is monitored and used as the indicator of crack growth. This can be done in solution while under cathodic protection to generate hydrogen at the crack tip, as shown schematically in Figure 1. RSL tests can be conducted in under a week and often times less than 24 hours depending on the severity of environment-induced material degradation. More detail on this test method is provided below.

The objective of this work was to determine the suitability of the RSL method for measuring $\mathrm{K}_{\mathrm{Th}}$ of $\mathrm{PH}$ Ni-base alloys and provide an initial ranking of alloys and alloy conditions. This is part of an on-going study to provide a fracture mechanics based metrics of HEAC resistance for alloys used oil and gas applications. 


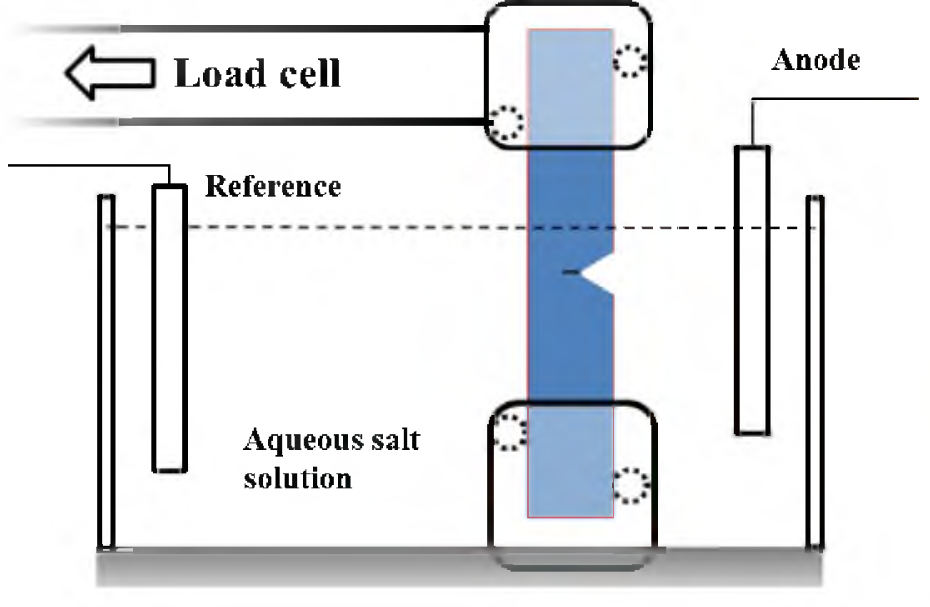

(a)

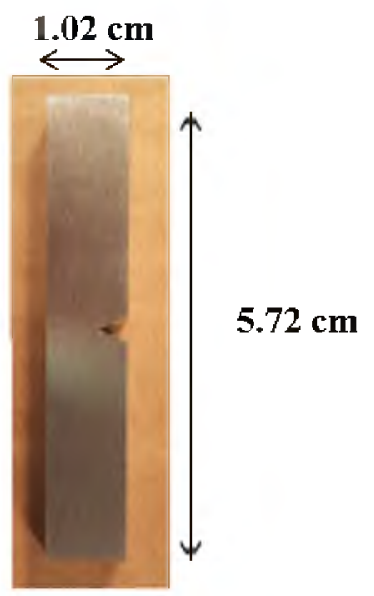

(b)

Figure 1: (a) Schematic of an RSL test unit used for hydrogen charging via cathodic protection and (b) an image of a standard RSL specimen.

\section{The Rising Step Load Method}

The rising step load technique has been standardized for use in measuring the threshold stress intensity factor for crack growth in the presence of hydrogen in ASTM Standard F1624[17]. According to this standard, under constant displacement a convex shape to the plot of load vs. time or a threshold value for the load drop indicates crack growth. Both indicators have been applied in the study of high strength stainless steels[18], [19]. An appropriate time per step is found by performing an initial test followed by a second test using a time per step that is at least doubled relative to the initial test. If second test does not measure a lower $\mathrm{K}_{\mathrm{Th}}$ relative to the first, the measured value of $\mathrm{K}_{\mathrm{Th}}$ is deemed invariant with time.

The low yield strength and hydrogen diffusivity of Ni-base $\mathrm{PH}$ alloys relative to age-hardened martensitic alloys presents unique challenges for this test method. Plastic deformation at the crack tip will be more pronounced as a result of the lower yield strength, leading to higher load drops for a given step that are unrelated to crack growth. Sufficient time must be provided in a given step for a critical hydrogen concentration to be reached at a critical distance ahead of the crack tip, such that $\mathrm{K}_{\mathrm{Th}}$ will be invariant with time. Once $\mathrm{K}_{\mathrm{Th}}$ has been reached, the subcritical crack growth rate will be limited by the rate of hydrogen diffusion ahead of the crack tip[20]. Thus, the required time per step and rate of load drop may be longer and slower, respectively, as a result of the relatively low hydrogen diffusivity.

A method employed in a prior study used the $1 \%$ load drop to indicate $\mathrm{K}_{\mathrm{Th}}$ [18]. Figure 2 shows a representative plot of the total load drop at each load step as a function of stress intensity factor for two tests; one exposed to hydrogen via in-situ cathodic charging and one not exposed to hydrogen. Points A and B represent the first load steps that pass the $1 \%$ load drop threshold for their respective tests, and thus points $\mathrm{C}$ and $\mathrm{D}$ would represent $\mathrm{K}_{\mathrm{Th}}$. Clearly though, point $\mathrm{C}$ deviates from the non-exposed specimen prior to $1 \%$ load drop. While a lower threshold value for load drop could be chosen, this assumes all alloys will demonstrate similar load drops when $\mathrm{K}_{\mathrm{Th}}$ is reached. In this work, in order to compensate for the anticipated difficulty in discerning if load drop was caused by crack tip plasticity or crack growth, $\mathbf{K}_{\text {Th }}$ was identified as the stress intensity factor of the step prior to the first step where the load drop of a specimen exposed to 
hydrogen clearly deviates from a non-exposed specimen. For example in Figure 2, the stress intensity factor of point $\mathrm{E}$ would be the measured $\mathrm{K}_{\mathrm{Th}}$. This analysis technique is termed the Clear Deviation (CD) method. Deviation from the air test as small as $0.1 \%$ load drop was considered clear. The $1 \%$ load drop threshold was also utilized, but in the form of a ratio between the stress intensity factors of the steps prior to $1 \%$ load drop for the two tests (K1\% ratio). The $\mathrm{K} 1 \%$ ratio is analogous to the relative measurements provided by the slow strain rate technique.

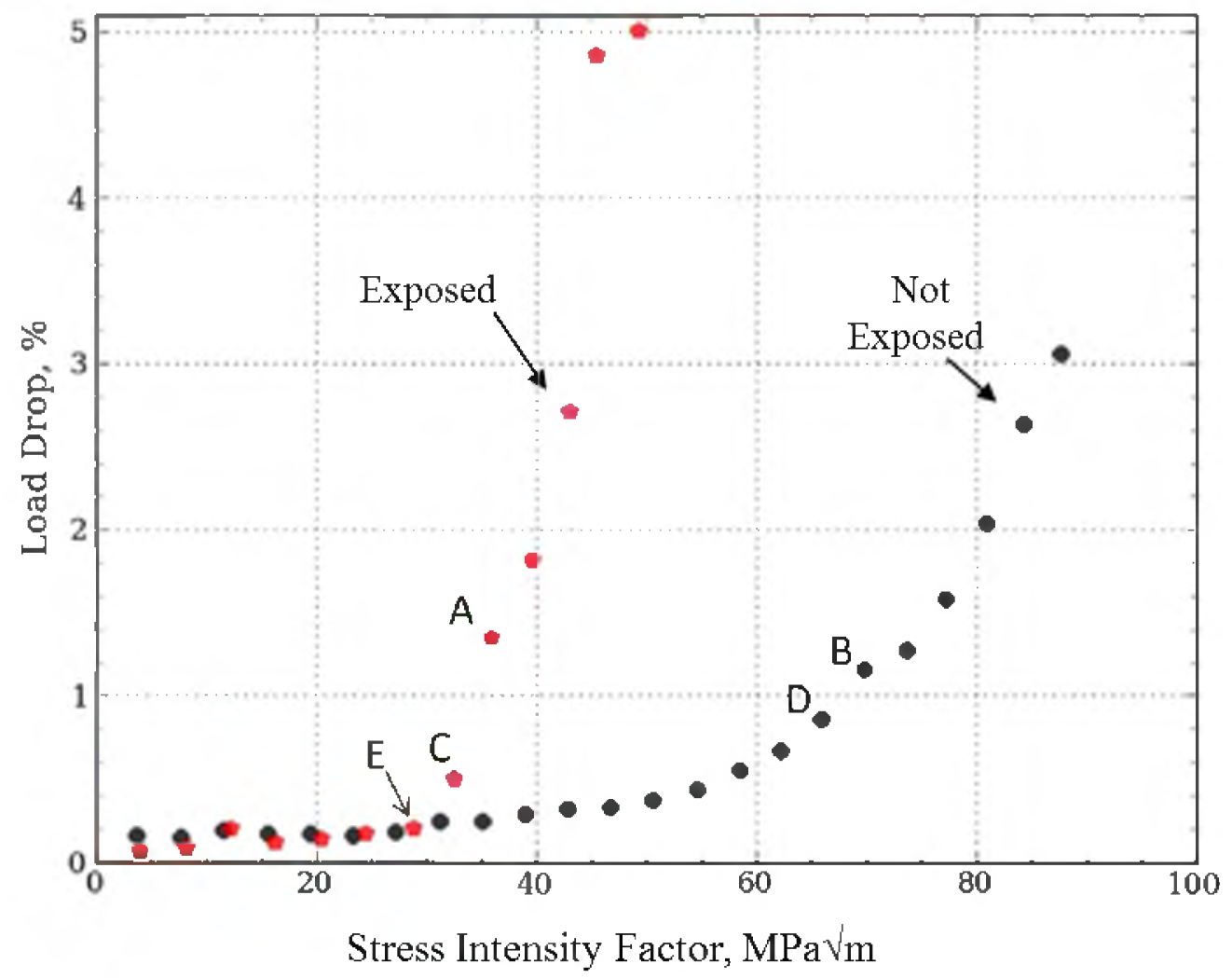

Figure 2: Example plot of load drop vs. stress intensity factor for two RSL tests: one where the specimen was exposed to hydrogen and one that was tested in air without hydrogen exposure. Points $A$ and $B$ correspond to the first points above 1\% load drop. Thus, the stress intensity factor at points $\mathrm{C}$ and $\mathrm{D}$ correspond to the values used for the $\mathrm{K} 1 \%$ ratio. Point $\mathrm{C}$ is also the first point of "clear" deviation, and so point $E$ is $K_{T h}$ according to the CD method.

\section{Experimental Procedure}

Measured compositions of alloy Pyromet ${ }^{\circledR} 718$ (718) and four variants of alloy UNS N07716 used in this study are shown in Table 1 . The composition of UNS N07716 with a higher Nbcontent (625P HS) is designed for $965 \mathrm{MPa}$ minimum yield strength compared to the $827 \mathrm{MPa}$ minimum for the standard composition (625P). Production heats of each material were vacuum induction melted followed by vacuum arc remelting before being forged down to $15-20 \mathrm{~cm}$ diameter round bar. Versions of UNS N07716 with higher C-content were also procured and tested. In addition to $\mathrm{C}$, the $\mathrm{S}$ and $\mathrm{Si}$-content was higher in these heats. 
Table I: Measured compositions of Ni-base PH superalloy heats.

\begin{tabular}{cccccccccccccc}
\hline Alloy & $\mathrm{C}$ & $\mathrm{Cr}$ & $\mathrm{Ni}$ & $\mathrm{Mo}$ & $\mathrm{Co}$ & $\mathrm{Al}$ & $\mathrm{Ti}$ & $\mathrm{Nb}$ & $\mathrm{Fe}$ & $\mathrm{Si}$ & $\mathrm{P}$ & $\mathrm{Cu}$ \\
\hline \hline 718 & 0.019 & 18.28 & 53.19 & 2.93 & 0.29 & 0.49 & 1.00 & 5.06 & 18.27 & 0.06 & 0.010 & 0.10 \\
625P & 0.008 & 20.97 & 60.59 & 8.00 & 0.03 & 0.21 & 1.29 & 3.40 & 5.21 & 0.03 & 0.002 & 0.01 \\
625P HS & 0.008 & 21.13 & 60.75 & 7.99 & 0.04 & 0.20 & 1.26 & 3.69 & 4.63 & 0.03 & 0.002 & 0.01 \\
625P High C & 0.015 & 20.83 & 61.87 & 8.00 & - & 0.20 & 1.16 & 3.36 & 4.365 & 0.13 & 0.010 & 0.06 \\
625P HS High C & 0.020 & 20.95 & 60.80 & 7.99 & - & 0.22 & 1.39 & 3.64 & 4.847 & 0.13 & 0.013 & - \\
\hline
\end{tabular}

Single edge notch bend specimens were removed from the mid-radius with a $\mathrm{C}-\mathrm{R}$ orientation The SENB specimens were $5.72 \mathrm{~cm}$ in length and $1.02 \mathrm{~cm}$ in both width and thickness Specimens were fatigue pre-cracked at room temperature in air until the pre-crack length was between $0.46-0.56 \mathrm{~cm}$. The stress intensity factor $(\mathrm{K})$ at the crack tip of the SENB specimens in four point bending was calculated using Equations 1 and 2,

$\mathrm{K}=\mathrm{C} \cdot \mathrm{P} \cdot(\pi \cdot \mathrm{a})^{0.5} \cdot \mathrm{f}(\mathrm{a} / \mathrm{W})$

where,

$\mathrm{f}(\mathrm{a} / \mathrm{W})=1.122-1.14(\mathrm{a} / \mathrm{W})+7.33(\mathrm{a} / \mathrm{W})^{2}-13.08(\mathrm{a} / \mathrm{W})^{3}+14(\mathrm{a} / \mathrm{W})^{4}$.

In the above equations, a is the crack length, $\mathrm{P}$ is the applied load, $\mathrm{W}$ is the specimen width and $\mathrm{C}$ is a constant that takes into account other geometric factors.

Table II: Heat treatments and measured yield strength of tested heats.

\begin{tabular}{ccc}
\hline ID & Heat treatment & $\begin{array}{c}\text { Yield Strength } \\
\text { (MPa) }\end{array}$ \\
\hline \hline $718 \mathrm{HT} 1$ & $968^{\circ} \mathrm{C} / 1 \mathrm{hr}+732^{\circ} \mathrm{C} / 8 \mathrm{hrs}+621^{\circ} \mathrm{C} / 8 \mathrm{hrs}$ & 1259 \\
$718 \mathrm{HT} 2$ & $1029^{\circ} \mathrm{C} / 1 \mathrm{hr}+788^{\circ} \mathrm{C} / 6 \mathrm{hr}$ & 854 \\
$718 \mathrm{HT} 3$ & $1029^{\circ} \mathrm{C} / 1 \mathrm{hr}+760^{\circ} \mathrm{C} / 6 \mathrm{hr}$ & 967 \\
$718 \mathrm{HT} 4$ & $1029^{\circ} \mathrm{C} / 1 \mathrm{hr}+732^{\circ} \mathrm{C} / 6 \mathrm{hr}$ & 904 \\
$718 \mathrm{HT} 5$ & $718^{\circ} \mathrm{C} / 8 \mathrm{hrs}+621^{\circ} \mathrm{C} / 8 \mathrm{hrs}($ direct aged) & 1265 \\
$625 \mathrm{P}$ & $1038^{\circ} \mathrm{C} / 1 \mathrm{hr}+732^{\circ} \mathrm{F} / 8 \mathrm{hrs}+621^{\circ} \mathrm{C} / 8 \mathrm{hrs}$ & 917 \\
$625 \mathrm{P} \mathrm{HS}$ & $1038^{\circ} \mathrm{C} / 1 \mathrm{hr}+760^{\circ} \mathrm{C} / 8 \mathrm{hrs}+649^{\circ} \mathrm{C} / 8 \mathrm{hrs}$ & 1051 \\
$625 \mathrm{P} \mathrm{High} \mathrm{C}$ & $1038^{\circ} \mathrm{C} / 2 \mathrm{hr}+732^{\circ} \mathrm{C} / 7 \mathrm{hrs}+621^{\circ} \mathrm{C} / 7 \mathrm{hrs}$ & 952 \\
$625 \mathrm{P} \mathrm{HS} \mathrm{High} \mathrm{C}$ & $1024-1052^{\circ} \mathrm{C} / 0.5-4 \mathrm{hr}+710-791^{\circ} \mathrm{C} / 0.5-$ & 1027 \\
\hline
\end{tabular}

Heat treatments of for each alloy are shown in Table II with room temperature yield strength measured on longitudinal tensile specimens taken adjacent to the RSL specimens. Heat treatment of 718 material was performed on specimen blanks whereas 625P and 625P HS were heat treated as the final step of the production process. $718 \mathrm{HT} 1$ is a standard heat treatment for aerospace grade material, following the AMS 5662 specification. The $968^{\circ} \mathrm{C}$ annealing temperature is designed to result in a relatively fine grained material with $\delta$-phase precipitates at the grain boundaries. The higher annealing temperature of $1029^{\circ} \mathrm{C}$ should result in increased 
grain size and solutioning of the $\delta$-phase, with ageing temperatures controlling the expected strength level. The direct aged version (718 HT5) skips the annealing step and is designed to reach the highest strength levels.

An increase in load of $1.81 \mathrm{~kg}$ per step was used for RSL testing. Tests finished once a load drop of $5 \%$ was reached or if the loading arm reached its maximum extension, which corresponded to an applied load of $>45 \mathrm{~kg}$. Specimens that remained in one piece after testing were manually fractured so that the fracture face could be examined. Specimens were immersed in $0.6 \mathrm{M} \mathrm{NaCl}$ solution with a $\mathrm{pH}$ of 5.5-8.5 for external hydrogen testing. Two voltages and step times were explored: $-1.1 \mathrm{~V}_{\mathrm{SCE}}$ with $3.5 \mathrm{~h}$ steps $\left(-1.1 \mathrm{~V}_{\mathrm{SCE}} / 3.5 \mathrm{~h}\right)$ to simulate in service galvanic coupling and $-1.4 \mathrm{~V}_{\mathrm{SCE}}$ with $1 \mathrm{~h}$ steps $\left(-1.4 \mathrm{~V}_{\mathrm{SCE}} / 1 \mathrm{~h}\right)$ to explore a more severe condition to determine if test time could be accelerated. Threshold stress intensity factors of specimens tested with external hydrogen are designated $\mathrm{K}_{\mathrm{Th}-\mathrm{E}}$.

SENB specimens of $718 \mathrm{HT} 1-3,625 \mathrm{P}$, and 625P HS were thermally pre-charged in gaseous hydrogen at a pressure of $83 \mathrm{MPa}$ for 280 hours at $200^{\circ} \mathrm{C}$. These charging conditions were chosen because a homogeneous concentration of hydrogen was achieved in Ni-201 in prior work under similar conditions[12]. These were then tested using step times of $1 \mathrm{~h}$ and $10 \mathrm{~h}$ in air. The $\mathrm{K}_{\mathrm{Th}}$ measured on internally charged specimens is designated $\mathrm{K}_{\text {Th-I }}$.

A JEOL scanning electron microscope (SEM) was used to analyze fracture surfaces. Grain size and other microstructural features were measured by optical microscopy after etching with Waterless Kalling's etchant $\left(5 \mathrm{~g} \mathrm{CuCl}_{2}+100 \mathrm{~mL} \mathrm{HCl}+100 \mathrm{~mL}\right.$ ethanol). Hydrogen content was measured by vacuum hot extraction (VHE) performed by Luvak, Inc.

\section{Results}

\section{Microstructure and Hydrogen Content}

ASTM grain size of 718 HT2-4 specimens were 3.5-4, while 718 HT1 and DA 718 were 6.5-7. Both 625P and 625P HS demonstrated ASTM grain sizes of 4.5-5. Measured yield strength of $1259 \mathrm{MPa}$ for $718 \mathrm{HT} 1$ was unusually high as typical yield strength for this condition is closer to $1138 \mathrm{MPa}$. Measured hydrogen content of thermally pre-charged 718 specimens varied from 41 wppm up to $55 \mathrm{wppm}$ whereas $625 \mathrm{P}$ and $625 \mathrm{P}$ HS specimens contained 60-64 wppm. An externally charged $718 \mathrm{HT} 1$ specimen after testing at $-1.4 \mathrm{~V}_{\mathrm{SCE}} / 1 \mathrm{~h}$ possessed an $\mathrm{H}$-content of 0.7 wppm, while a non-exposed specimen of the same material and condition demonstrated 0.5 wppm H.

\section{Threshold Stress Intensity Factor}

Measured $\mathrm{K}_{\mathrm{Th}-\mathrm{E}}$ and $\mathrm{K} 1 \%$ ratio for the RSL tests as a function of yield strength are shown in Figure $3(\mathrm{a})$ and (b), respectively. $\mathrm{K}_{\mathrm{Th}-\mathrm{E}}$ of the $-1.1 \mathrm{~V}_{\mathrm{SCE}} / 3.5 \mathrm{~h}$ generally shows the expected trend with strength with the exception of $718 \mathrm{HT} 5$, which has a $\mathrm{K}_{\text {Th-E }}$ that is $18 \mathrm{MPaVm}$ higher than $718 \mathrm{HT} 1$ with a similar yield strength. The $\mathrm{K} 1 \%$ ratios of the $-1.1 \mathrm{~V} / 3.5 \mathrm{~h}$ test suggests there was a significant increase in the susceptibility of 625P HS relative to the lower strength condition and all conditions of 718 . With the $-1.4 \mathrm{~V}_{\mathrm{SCE}} / 1 \mathrm{~h}$ testing conditions $\mathrm{K}_{\mathrm{Th}-\mathrm{E}}$ of $718 \mathrm{HT} 2-4$ decreased, the higher strength conditions (HT1 and HT5) were not affected, and 625P improved while 625P HS saw a moderate decline. The relatively high $\mathrm{K}_{\text {Th-E }}$ of $718 \mathrm{HT} 1$ contradicts prior notions of the deleterious effect of $\delta$-phase. Finally, the results on specimens that were thermally pre-charged 
and tested with $1 \mathrm{~h}$ step times demonstrate the expected trend for the 718 specimens as the highest strength $718 \mathrm{HT} 1$ displays the lowest $\mathrm{K}_{\text {Th-I }}$. Thermally pre-charged 625P and 625P HS performed favorably relative to 718 . Because the hydrogen is present before load is applied, this could be considered the most consistent comparison of these alloys as hydrogen diffusion is likely not significantly impacting these results. Increasing step time to $10 \mathrm{~h}$ did not affect 718 $\mathrm{K}_{\text {Th-I }}$, while $625 \mathrm{P}$ and $625 \mathrm{P}$ HS saw a moderate increase of $7 \mathrm{MPaVm}$ and decrease of $4 \mathrm{MPaVm}$, respectively.
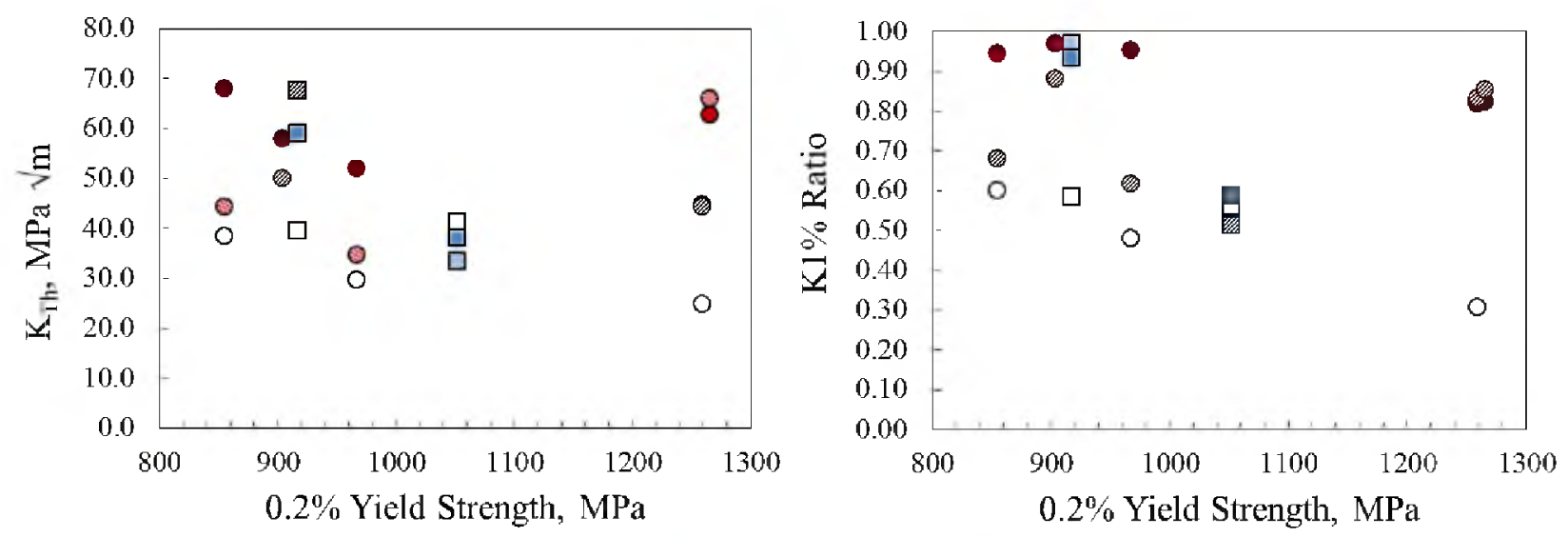

- $718-1.1 \mathrm{~V}_{\mathrm{SCE}} / 3.5 \mathrm{~h} \quad \square 625 \mathrm{P}-1.1 \mathrm{~V}_{\mathrm{SCE}} / 3.5 \mathrm{~h} \quad 0718-1.4 \mathrm{~V}_{\mathrm{SCE}} / 1 \mathrm{~h} \quad \square 625 \mathrm{P}-1.4 \mathrm{~V}_{\mathrm{SCE}} / 1 \mathrm{~h} \quad 0718$ Int. $\square 625 \mathrm{P}$ Int.

Figure 3: Results of RSL external and internal hydrogen testing on Ni-base superalloys 718 and $625 \mathrm{P}$ showing (a) $K_{T h}$ and (b) the $K 1 \%$ ratio as a function of yield strength.

SEM images of the fracture surface of $718 \mathrm{HT} 1$ after a $-1.4 \mathrm{~V}_{\mathrm{SCE}} / 1 \mathrm{~h}$ test is shown in Figure 4. Directly ahead of the pre-crack (Figure 4(a)) an intergranular fracture surface is seen, corresponding to HEAC. The fracture mechanism eventually shifts to microvoid coalescence (Figure 4(b)). These images are representative of the all specimens that showed embrittlement by external hydrogen. The length of the intergranular zone varied from $0.3 \mathrm{~mm}$ for $718 \mathrm{HT} 1$ after a $-1.4 \mathrm{~V}_{\mathrm{SCE}} / 1 \mathrm{~h}$ test, up to $1.7 \mathrm{~mm}$ for $625 \mathrm{P} \mathrm{HS}$ after either $-1.4 \mathrm{~V}_{\mathrm{SCE}} / 1 \mathrm{~h}$ or $-1.1 \mathrm{~V}_{\mathrm{SCE}} / 3.5 \mathrm{~h}$ tests. This indicates that hydrogen is not penetrating fully and homogenously into the material in the time it takes to run an external hydrogen test. Internally charged specimens showed intergranular fracture over the entire fracture surface.
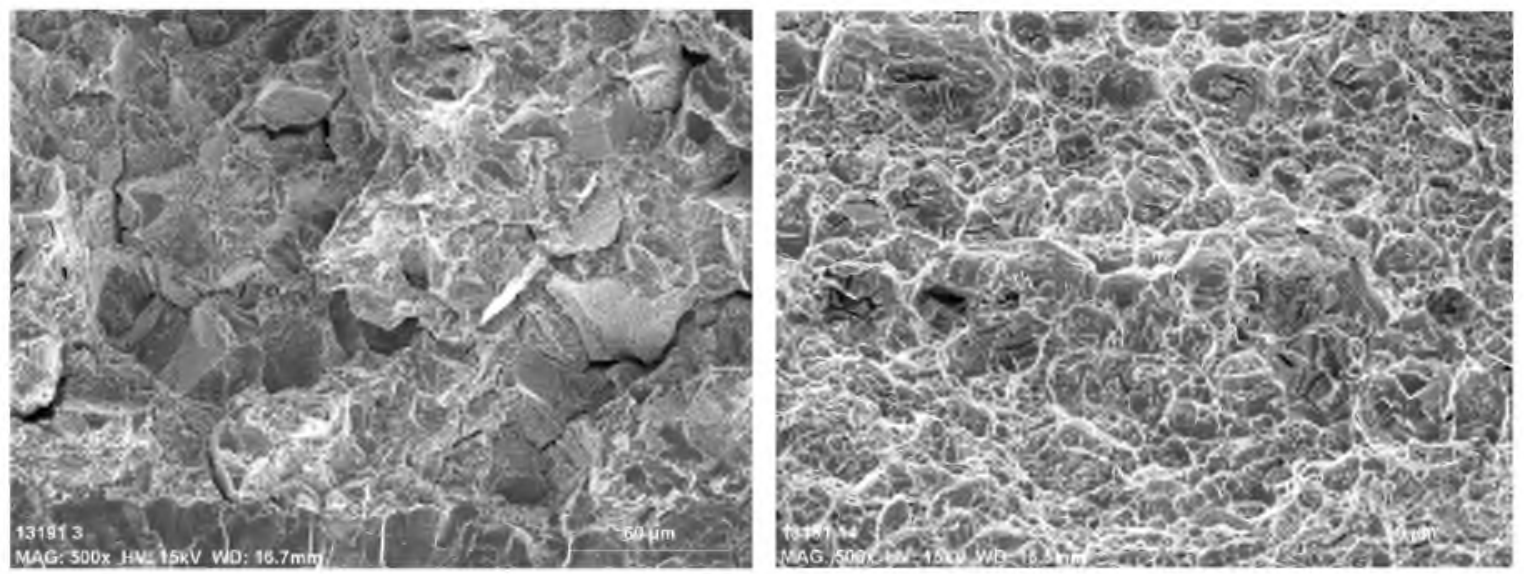

Figure 4: SEM images of fracture surface of $718 \mathrm{HT}$ specimen after $-1.1 \mathrm{~V}_{\mathrm{SCE}} / 3.5 \mathrm{~h}$ test (a) directly ahead of the pre-crack showing mostly intergranular fracture and (b) once the fracture has changed to microvoid coalescence. Direction of crack growth is in the upward direction relative to the images. 


\section{Effect of Dwell Time}

The performance of 718 HT1 in external hydrogen is surprising given the strength level and expected microstructure. While the results of the external hydrogen and internal hydrogen testing do not have to be equivalent, the significant discrepancy between $\mathrm{K}_{\text {Th-E }}$ and $\mathrm{K}_{\text {Th-I }}$ of 718 HT1 suggests the step times used with the external hydrogen testing were not sufficiently long or the measurement technique was not sensitive enough for 718 in this condition. Another possibility for the measured $\mathrm{K}_{\mathrm{Th}-\mathrm{E}}$ of $718 \mathrm{HT} 1$ is crack tip occlusion, which has been attributed with inflating $\mathrm{K}_{\mathrm{Th}}$ of alloy 718 in a similar condition[9]. In order to determine if a longer step time would result in lower a lower $\mathrm{K}_{\mathrm{Th}}$, a specimen was step loaded to $12.7 \mathrm{~kg}(29.7 \mathrm{MPaVm})$ in 1.81 $\mathrm{kg} / \mathrm{h}$ steps and then held for 70 hours under $-1.1 \mathrm{~V}_{\mathrm{SCE}}$, for a total charge time of 77 hours. The plot of load drop as a function of time for the $70 \mathrm{~h}$ hold is shown in Figure 5. The first 26 hours show an initial load drop attributed to plastic deformation at the crack tip. Approaching 26 hours, the load drop abruptly increases, followed by an approximately two hour period where the slope is approximately $80 \%$ of the slope of the 18 hours prior to the abrupt increase. Between 30 and 31 hours, the slope changes once again and the load drop increases at a rate 2.5 times faster than the 18 hours prior to the abrupt increase.

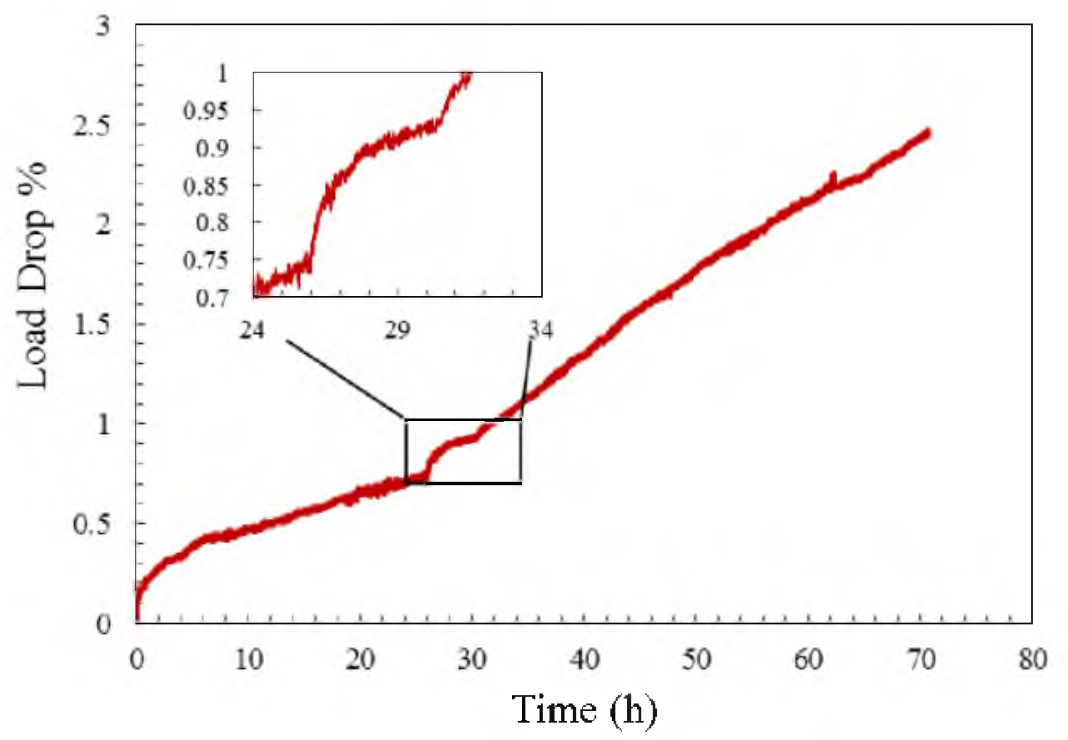

Figure 5: Load drop of 718 HT1 while being held in displacement control for 70 hours under $-1.1 V_{\text {SCE. }}$ The inset shows an event that may correspond to crack growth.

The load drop data collected suggests a change in relaxation mechanism at 26 hours that may be due to crack growth. The abrupt increase and subsequent return to the previous rate of load drop may be a result of hydrogen reaching a required concentration at a critical distance ahead of the crack tip, leading to crack growth and temporary crack arrest as the crack tip reaches regions with lower H-content. This is followed by a period of further charging before a steady state is reached between crack growth and hydrogen diffusion ahead of the crack tip. This does not agree with a visual observation of the pre-crack before and after the test, but optical microscopy may have been unable to resolve the growth or crack growth did not occur on the face of the specimen examined. 
By using the limiting assumption that the stress intensity factor remains constant even after crack growth, an upper bound for total crack growth can be calculated using Equations 1 and 2. In this case, the total load drop from the event at 26 hours until the end of the test was $0.64 \mathrm{~kg}$. This would result in a crack growth of approximately $160 \mu \mathrm{m}$. If the relaxation mechanism causing the load drop before the event at 26 hours was assumed to continue to contribute, the load drop due to the presumed crack growth would be $0.29 \mathrm{~kg}$, corresponding to crack growth of $\sim 70 \mu \mathrm{m}$. Because the stress intensity factor at the crack tip will decrease as the crack grows, the crack extension would be even smaller. This is on the scale of a few grains for this material. If valid, this indicates the load drop measurement is sensitive enough for 718 in the higher strength condition, and longer hold times should be used to allow sufficient time for hydrogen diffusion.

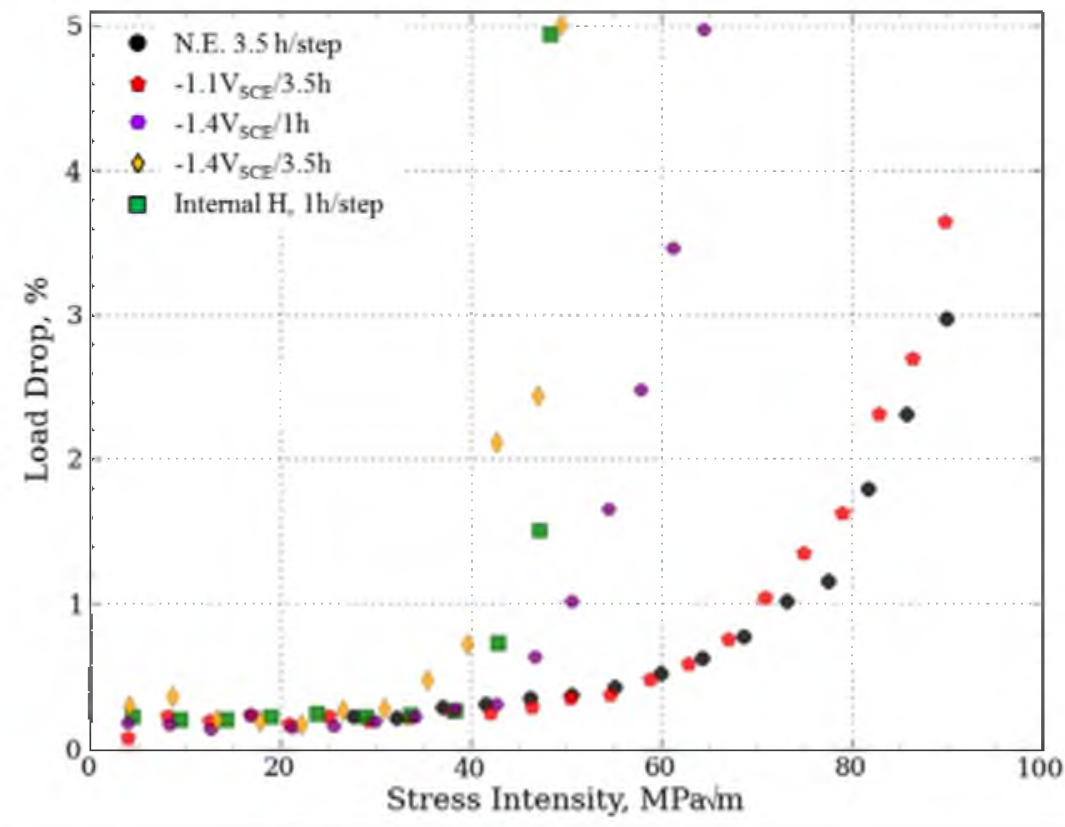

Figure 6: Load drop as a function of stress intensity factor for 718 HT2 using various methods of hydrogen delivery.

Further work was undertaken on understanding the effects of time and applied potential on the measured $\mathrm{K}_{\text {Th }}$ by testing $718 \mathrm{HT} 2$ at $-1.4 \mathrm{~V}_{\mathrm{SCE}}$ with $3.5 \mathrm{~h}$ steps $\left(1.4 \mathrm{~V}_{\mathrm{SCE}} / 3.5 \mathrm{~h}\right)$. Representative load drop plots of 718 HT2 tested in all four hydrogen charging conditions and when not exposed (N.E.) to hydrogen are shown in Figure 6. As reported above and shown here, the $-1.4 \mathrm{~V}_{\mathrm{SCE}} / 1 \mathrm{~h}$ test is more severe than the $-1.1 \mathrm{~V}_{\mathrm{SCE}} / 3.5 \mathrm{~h}$ test. The susceptibility to HEAC increases further in the $-1.4 \mathrm{~V}_{\mathrm{SCE}} / 3.5 \mathrm{~h}$ test with a measured $\mathrm{K}_{\text {Th-E }}$ of $31.1 \mathrm{MPaVm}$, which shows even more severe embrittlement relative to the internally charged specimen. Thus, the $1 \mathrm{~h}$ and $3.5 \mathrm{~h}$ step time may be insufficient for determination of an invariant $\mathrm{K}_{\mathrm{Th}}$ for this alloy.

\section{Trace Element Variation}

Variants of 625P and 625P HS with higher C-contents were tested to ascertain the effect of carbide precipitation on HEAC resistance. Mechanical properties of the four heats are shown in Table III. Mechanical properties are close between the low and high carbon versions of each alloy with the exception of the Charpy V-notch (CVN) impact toughness, which drops by 25 $30 \%$ with higher carbon content. 
Table III: Mechanical properties of 625P alloys tested for HEAC resistance.

\begin{tabular}{ccccccc}
\hline \multirow{2}{*}{ Alloy } & Condition & YS (ksi) & TS (ksi) & El (\%) & RA(\%) & $\begin{array}{c}\text { CVN (a)-60 } \\
(\mathrm{J})\end{array}$ \\
\hline \hline $625 \mathrm{P}$ & Low Carbon & 917 & 1227 & 31 & 48 & 96 \\
$625 \mathrm{P}$ & High Carbon & 952 & 1289 & 32 & 44 & 64 \\
$625 \mathrm{P} \mathrm{HS}$ & Low Carbon & 1051 & 1331 & 31 & 45 & 64 \\
625P HS & High Carbon & 1027 & 1276 & 30 & 44 & 38 \\
\hline
\end{tabular}

Optical micrographs of the low $\mathrm{C}$ and high $\mathrm{C}$ versions of 625P HS are shown in Figure 7 (a) and (b), respectively. Image analysis filters were used to highlight precipitates visible at this magnification. The higher carbon bearing heats qualitatively have a higher number and area fraction of precipitates and tend to be nearly continuous on the grain boundaries. Semiquantitative analysis estimates the area fraction covered by precipitates to be $2-4 \%$ for the low $\mathrm{C}$ 625P HS and 3.5-7\% for the high C 625P HS. ASTM grain size was measured to be $4.5-5$ for all four specimens.
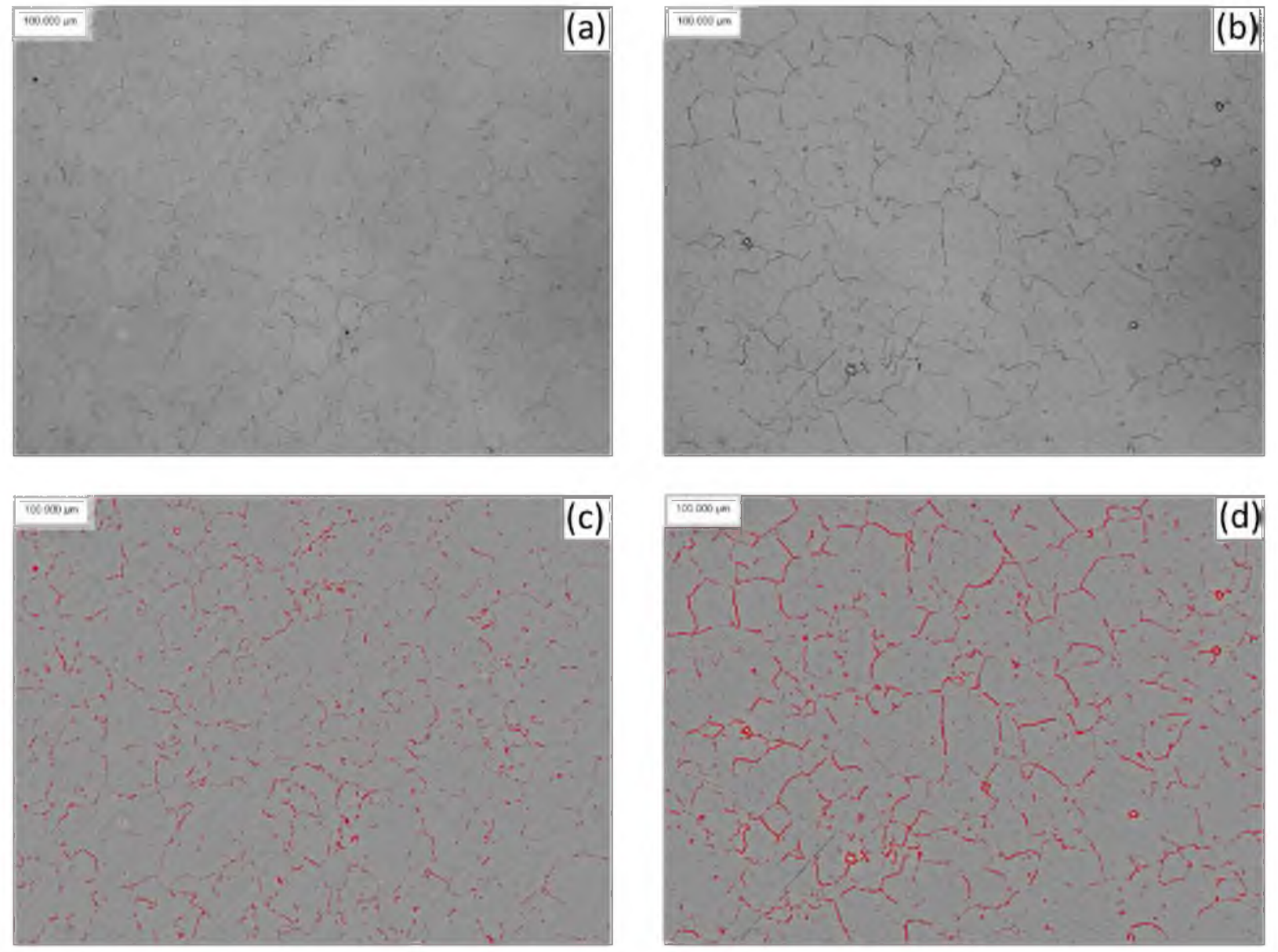

Figure 7: Optical micrographs of (a) 625P HS and (b) 625P HS High C. In (c) and (d), precipitation is highlighted by image analysis to show the difference in severity of grain boundary precipitation for the low carbon and high carbon variants, respectively. 
Table IV displays the results for external hydrogen testing on the UNS N07716 variants. In both test conditions the higher carbon bearing heats display lower $\mathrm{K}_{\mathrm{Th}-\mathrm{E}}$. This result is attributed to an increase in grain boundary precipitation weakening the grain boundary at the carbide/grain interface, leading to grain boundary decohesion. The combination of strong hydrogen trapping by the precipitates and their location at the grain boundary may explain this behavior[14]. The effect of $\mathrm{Si}, \mathrm{P}$, and slight variations in the heat treatment also should not be ignored as potential factors. Regardless of cause, the results point to the importance of microstructure and chemistry. Both alloys would fall within the UNS N07716 specification, yet the embrittlement response can vary significantly, especially in the case of the lower strength condition.

Table IV: Results of RSL testing on heats of 625P in external hydrogen.

\begin{tabular}{|c|c|c|c|c|c|}
\hline & & \multicolumn{2}{|c|}{$\mathrm{K}_{\mathrm{Th}-\mathrm{E}}, \mathrm{MPaVm}$} & \multicolumn{2}{c|}{$\mathrm{K} 1 \%$ Ratio } \\
Alloy & Carbon Level & $-1.4 \mathrm{~V}_{\mathrm{SCE}} / 1 \mathrm{~h}$ & $-1.1 \mathrm{~V}_{\mathrm{SCE}} / 3.5 \mathrm{~h}$ & $-1.4 \mathrm{~V}_{\mathrm{SCE}} / 1 \mathrm{~h}$ & $-1.1 \mathrm{~V}_{\mathrm{SCE}} / 3.5 \mathrm{~h}$ \\
\hline $625 \mathrm{P}$ & Low Carbon & 67.7 & 59 & 0.969 & 0.934 \\
$625 \mathrm{P}$ & High Carbon & 27.7 & 25.7 & 0.45 & 0.436 \\
$625 \mathrm{P} \mathrm{HS}$ & Low Carbon & 33.4 & 38.3 & 0.515 & 0.588 \\
$625 \mathrm{P} \mathrm{HS}$ & High Carbon & 24.3 & 25.7 & 0.342 & 0.346 \\
\hline
\end{tabular}

\section{Conclusions}

In this study, the RSL technique was used to measure the HEAC resistance of alloys Pyromet ${ }^{\circledR}$ 718 and UNS N07716 in various conditions. The technique was shown capable of measuring $\mathrm{K}_{\mathrm{Th}}$ and the following conclusions could be made:

- The RSL method is capable of discerning differences between HEAC resistance of Nibase PH superalloys. The tests provide fracture mechanics based values and can be completed in a number of days.

- HEAC resistance shows in an inverse relationship with strength for most conditions of 718 and $625 \mathrm{P}$. Testing with internal hydrogen indicates $625 \mathrm{P}$ has a favorable combination of strength and HEAC resistance relative to 718 .

- Additional work is required to determine the cause of the unexpectedly high $\mathrm{K}_{\mathrm{Th}-\mathrm{E}}$ of alloy 718 in the highest strength conditions.

- Higher carbon content in $625 \mathrm{P}$ and the resulting increase in continuous grain boundary carbides correlates with a lower $\mathrm{K}_{\mathrm{Th}-\mathrm{E}}$, suggesting performance of the alloy is dependent on composition and microstructure.

Future work will explore the step times required to find invariant $\mathrm{K}_{\mathrm{Th}}$ for a number of simulated galvanic couples and results will be verified by slow strain rate testing. A standardized, quantitative method to find $\mathrm{K}_{\mathrm{Th}}$ will also be developed. Testing of more alloys and alloy conditions is on-going, with the goal of characterizing commercially relevant alloys that have potential to be used in environments containing hydrogen.

\section{References}

[1] J. Moreno-Trejo and T. Markeset, "Identifying Challenges in the Maintenance of Subsea Petroleum Production Systems," Adv. Prod. Manag. Syst., vol. 384, pp. 251-259, 2012. 
[2] B. Craig, "Materials for Deep Oil and Gas Well Construction," Adv. Mater. Process., pp. $33-35,2008$.

[3] T. Cassagne, M. Bonis, D. Hillis, and C. Duret, "Understanding Field Failures of Alloy 718 Forging Materials in HP / HT wells," in EuroCorr 2008, EFC, 2008, pp. 1-13.

[4] S. Mannan, "Alloy 718 for oilfield applications," Journal of Metals, vol. 64, pp. 265-270, 2012 .

[5] R. Walter and W. Chandler, "Influence of Gaseous Hydrogen on Metals: Final Report (NASA CR-124410)," 1973.

[6] L. Fournier, D. Delafosse, and T. Magnin, "Cathodic hydrogen embrittlement in alloy 718," Mater. Sci. Eng. A, vol. 269, no. 1-2, pp. 111-119, 1999.

[7] P. D. Hicks and C. J. Altstetter, "Hydrogen-Enhanced Cracking of Superalloys," Metall. Trans. A, vol. 23, pp. 237-249, 1992.

[8] L. Liu, K. Tanaka, A. Hirose, and K. F. Kobayashi, "Effects of precipitation phases on the hydrogen embrittlement sensitivity of Inconel 718," Sci. Technol. Adv. Mater., vol. 3, no. 4, pp. 335-344, Dec. 2002.

[9] J. A. Lillard, R. G. Kelly, and R. P. Gangloff, "Effect of electrode Potential on Stress Corrosion Cracking and Crack Chemistry of a Nickel-Base Superalloy," in Corrosion 97 , 1998, no. 197, pp. 197/1-197/26.

[10] F. Galliano, B. Ter-Ovanessian, E. Andrieu, J.-M. Cloue, C. Baret-Blanc, and G. Odemer, "On the Influence of Temperature on Hydrogen Embritllement Susceptibility of Alloy 718," in Superalloy 718 and Derivatives, 2010, pp. 933-945.

[11] C. San Marchi and B. P. Somerday, "Technical Reference on Hydrogen Compatibility of Materials (SAND2008-1163)," 2008.

[12] S. Bechtle, M. Kumar, B. P. Somerday, M. E. Launey, and R. O. Ritchie, "Grainboundary engineering markedly reduces susceptibility to intergranular hydrogen embrittlement in metallic materials," Acta Mater., vol. 57, no. 14, pp. 4148-4157. 2009.

[13] D. M. Symons, "A comparison of internal hydrogen embrittlement and hydrogen environment embrittlement of X-750," Eng. Fract. Mech., vol. 68, no. 6, pp. 751-771, 2001.

[14] D. Symons, G. Young, and J. Scully, "The effect of strain on the trapping of hydrogen at grain-boundary carbides in Ni-Cr-Fe alloys," Metall. Mater. Trans. A, vol. 32, no. 2, pp. 369-377, 2001.

[15] ASTM Standard E1681, "Standard Test Method for Determining Threshold Stress Intensity Factor for Environment-Assisted Cracking of Metallic Materials," 2014. 
[16] NACE Standard TM0177, "Laboratory Testing of Metals for Resistance to Sulfide Stress Cracking and Stress Corrosion Cracking in H2S Environments," 2005.

[17] ASTM Standard F1624, "Standard Test Method for Measurement of Hydrogen Embrittlement Threshold in Steel by Incremental Step Loading Technique," 2007.

[18] D. E. Wert and T. N. Werley, "Comparison of Stress Corrosion Cracking and Hydrogen Embrittlement Resistance of High Strength Aerospace Alloys," TMS 2010 Conference, Seattle, USA, February, 2010.

[19] P. Tyler, M. Levy, and L. Raymond, "Investigation of the conditions for crack propagation and arrest under cathodic polarization by rising step load bend testing," Corrosion, vol. 47, pp. 82-87, 1991.

[20] R. P. Gangloff, "Diffusion Control of Hydrogen Environment Embrittlement in High Strength Alloys," in in Hydrogen effects on material behavior and corrosion deformation interactions, N. R. Moody, A. W. Thompson, R. Ricker, G. Was, and R. Jones, Eds. Jackson Hole, Wyoming, 2003, pp. 477-497. 